\title{
MOUREANTHIDIUM, GEN.N. DE DIANTHIDIINI DO BRASIL (HYMENOPTERA, MEGACHILIDAE) 1
}

\author{
Danúncia Urban ${ }^{2}$
}

\begin{abstract}
MoUREANTHIDIUM, Gen.n. OF Dianthidini from Brazil. (Hymenoptera, Megachilidae). Moureanthiditum, gen.n. is proposed for Dianthidium subarenarium Schwarz, 1933 and to include four new species of Anthidiine bees from Brazil, Moureanthidium paranaense, sp.n from Ponta Grossa, Paraná, Moureanthidium capixaba, sp.n. from Santa Teresa, Espírito Santo, Moureanthidium bahianum, sp.n. from Vitória da Conquista, Bahia and Moureanthidium catarinense, sp.n. from Seara, Santa Catarina. The males are characterized by the border of the seventh tergum strongly reflexed, densely hairy and with a pair of lateral projections and the third sternite with two spines or little projections at the middle, near the apex.

KEY WORDS. Moureanthidium, Anthidiinae, Megachilidae, Hymenoptera,

Taxomomy, new genus
\end{abstract}

SCHWARZ (1933) descreveu Dianthidium subarenarium, baseado em um exemplar coletado no Brasil, sem contudo dar a conhecer a localidade por não ter conseguido decifrar a etiqueta. Padre. J.S. Moure examinou o tipo, com o $\mathrm{n}^{\circ}$ 17.A. 1921, no Museu Britânico e ao comparar com um macho coletado em Seara (Nova Teutônia), Santa Catarina, concluiu tratar-se da mesma espécie.

\section{Moureanthidium, gen.n.}

Fig. 2

Espécie tipo: Dianthidium subarenarium Schwarz, 1933

Macho. Tegumento brilhante e densamente marcado por pontos grandes na fronte, vértice, mesoscuto e escutelo, onde os pontos quase igualam um terço do diâmetro do ocelo mediano e os intervalos menores que meio diâmetro de ponto; no restante da cabeça e mesosoma os pontos um poco menores; tergos basais com pontuação densa, os pontos medindo aproximadamente um terço do diâmetro dos pontos da fronte e, os intervalos inferiores ao diâmetro dos pontos. Cabeça com cerdas lisas alongadas na fronte e vértice, as cerdas eretas e finas no mesoscuto e escutelo; lado ventral do mesosoma com pêlos plumosos; nos tergos muito curta e lisa todavia mais longa nos flancos, densa e plumosa no bordo e nas projeções laterais do sétimo tergo, com cerdas e pêlos plumosos levemente arqueados para

1) Contribuição número 818 do Departamento de Zoologia, Universidade Federal do Paraná.

2) Departamento de Zoologia, Universidade Federal do Paraná, Caixa Postal 19020, 81531-990 Curitiba, Paraná, Brasil. 
a frente no sexto e sétimo tergos; no segundo esterno densa, ereta e muito curta, no terceiro plumosa e decumbente, também nos flancos do quarto e nas projeções digitiformes laterais do quinto esterno.

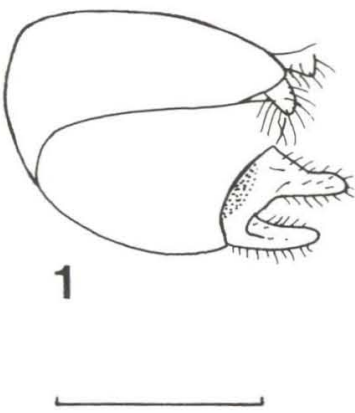

$1 \mathrm{~mm}$

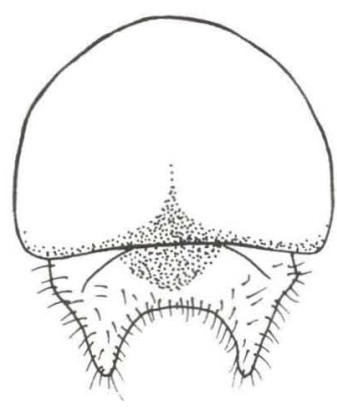

2

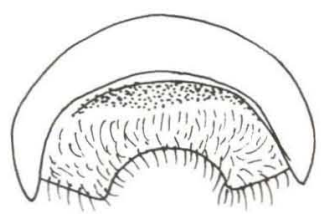

3

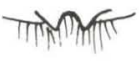

4
5

Figs 1-5. (1) Moureanthidium paranaense, vista lateral do ápice do metasoma (quinto ao sétimo tergo) com as projeções laterais do quarto e quinto esternos; (2) M. subarenarium, sexto e sétimo tergos sendo o sexto no maior comprimento: (3) $M$. capixaba, vista posterior do sexto e sétimo tergos, no sétimo evidenciando a parte apical dos lobos; (4) $M$. paranaense, ápice do terceiro esterno com as projeções medianas subapicais; (5) $M$. catarinense, coxa posterior com lâmina digitiforme.

Mandibulas tridentadas, os dentes equidistantes, com carena látero-external forte e quase unida à carena externa superior na base, as carenas inferiores quase até a metade da mandíbula, com pontos grandes alongados e rugosidades irregulares na base até a carena látero-external e no restante com pontos grandes esparsos e rugosidades fracas em direção aos dentes mediano e interno. Clípeo quase achatado, deprimido no ápice e com tubérculos pequenos na margem apical que sobressaem à base do labro; suturas subantenais não evidentes; carenas interalveolares curtas e fortemente divergentes na fronte, projetadas para cima e tão afastadas uma da outra na área supraclipeal quanto duas vezes seu comprimento; sem carena frontal; com carenas paroculares; genas largas junto ao vértice e diminuindo muito em direção às mandíbulas; carena hipostomal forte. Antenas com o escapo pouco mais longo que a distância interalveolar, três flagelômeros basais tão longos como seu diâmetro, os quatro apicais mais longos que seu diâmetro.

Pronoto com lâmina translúcida para cima e um pouco inclinada para a frente nos lobos, quase reta e terminando bem antes do mesoscuto. Mesepisternos com carena pré-episternal na metade dorsal. Mesoscuto quase tão longo como largo ao nível das tégulas, expandido aos lados em lâmina voltada para cima; escutelo arredondado posteriormente com emarginação mediana, expandido em lamela aos lados e sobressaindo ao metanoto; base do escutelo deprimida e brilhante entre as axilas exceto no meio; axilas com o bordo livre mais longo que a sutura escutelo-axilar, não projetadas para trás. Tégulas arredondadas e sem emarginação posterior. Asas anteriores com a bifurcação entre a média e a cubital coincidindo 
com a transversal cúbito-anal; asas posteriores com o lobo jugal mais longo que um terço do lobo anal; coxas posteriores com lâmina dentiforme voltada para baixo no lado interno; tarsômeros posteriores alongados, o basitarso mais curto que a soma do comprimento dos três tarsômeros seguintes; com arólio entre as garras. Propódeo vertical com base foveolada, as fovéolas irregulares, menores no meio; espiráculo propodeal carenado com larga área posterior brilhante irregularmente foveolada e limitada por carena.

Tergos metasomáticos com depressão marginal estreita nos flancos do primeiro ao quinto; sexto longo e voltado para a frente, com depressão marginal completa, mais larga e um pouco angulosa no meio e orla lisa elevada em lâmina quase até os flancos; sétimo tergo disposto ventralmente, com área mediana deprimida achatada não chegando ao bordo, duas projeções digitiformes longas laterais, uma larga emarginação quase circular separando as projeções laterais e larga área ventral; esterno hasal com carena laminada mediana no terço basal e um pouco inflado aos lados no disco; segundo pouco inflado nos flancos, no disco; terceiro com duas pequenas projeções curtas medianas espiniformes subapicais; quarto estreitado medianamente com o bordo em ângulo muito aberto, com tubérculo carenado nos flancos; quinto esterno deprimido subapicalmente, o ápice projetado para baixo em ângulo reto e duas projeçoes digitiformes carenadas nos flancos.

Fêmea semelhante ao macho, difere nas estruturas a seguir relacionadas: mandibulas com quatro dentes apicais, os dois basais rasos; carena látero-external e externa inferior ultrapassando a metade do comprimento da mandíbula; sexto tergo sem carena mediana, um pouco deprimido subapicalmente e o ápice elevado; sexto esterno normal; pernas com arólio vestigial.

Comentário. Pertence ao grupo de Dianthidiini em que os machos tem arólio e a fêmea apenas uma projeção entre as garras.

Moureanthidium, gen.n. é reconhecido pelas carenas interalveolares curtas projetadas para cima e fortemente divergentes; carena pré-episternal até o meio dos mesepisternos; escutelo achatado e a densa pontuação dos tergos. O macho com o sexto tergo longo, voltado para a frente e com ápice projetado em lâmina; sétimo tergo disposto ventralmente, com área mediana deprimida achatada quase até o bordo e distalmente com duas projeções digitiformes ou lobos angulosos. Dicranthidium Moure \& Urban, 1975, distingue-se pelas duas projeções digitiformes e duas áreas deprimidas subapicais no sétimo tergo, e do quarto ao sexto tergo com projeções laterais encaixadas em repouso; os esternos de Moureanthidium são visíveis e, os tergos não apresentam projeções laterais. Machos de Hypanthidiodes Moure, 1947 e Moureanthidium tem em comum os tarsômeros posteriores longos, o basitarso mais curto que a soma dos três tarsômeros medianos. Do grupo de gêneros com redução das estruturas do arólio só nas fêmeas, Moureanthidium distingue-se pela pontuação muito densa nos tergos; carenas interalveolares curtas e divergentes. Dicranthidium distingue-se pela carena pré-episternal quase completa; Hypanthidiodes pela carena pré-episternal longa e escutelo bigiboso; Anthidulum Michener, 1948 pelas carenas interalveolares curtas e área supraclipeal em parte lisa; Michanthidium Urban, 
1994 pelas mandíbulas de bordo liso e apenas com dois pequenos dentes distais; Ctenanthidium Urban, 1991 com arólio pequeno distingue-se pelo mesoscuto alongado, mais longo que largo.

Etimologia. O gênero é dedicado ao Prof. Dr. Pe. Jesus S. Moure por sua contribuição ao conhecimento dos Apoidea neotropicais.

Chave para as espécies de Moureanthidium

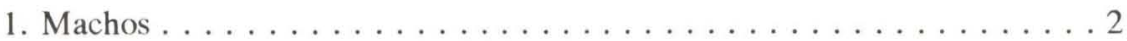

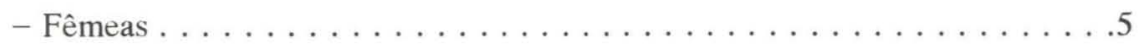

2. Sétimo tergo bilobado, com larga emarginação circular separando os lobos

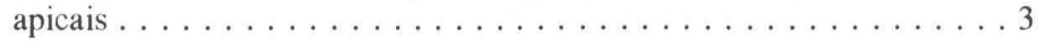

- Sétimo tergo com duas projeções digitiformes laterais longas, amplamente

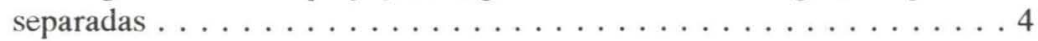

3. Faixa amarela pós-ocelar do vértice prolongada atrás dos olhos apenas nos cantos superiores. Margem do quarto ao sexto tergo translúcida amarelo-acastanhada. Tégulas de um castanho enegrecido. Espírito Santo e Rio de Janeiro. capixaba

- Faixa amarela pós-ocelar do vértice prolongada nas genas além da metade do comprimento dos olhos, e outra área amarela genal junto à articulação mandibular. Margem do quarto ao sexto tergo enegrecida. Tégulas de um castanho amarelado. Santa Catarina . . . . . . . . . . catarinense

4. Quinto esterno com duas áreas discais infladas aos lados. Lâmina das coxas posteriores em dente subapical projetado para baixo e para trás e formando carena para a base. Paraná . . . . . . . . . . . . paranaense

- Quinto esterno sem áreas infladas laterais, com depressão subapical. Lâmina basal dentiforme nas coxas posteriores. São Paulo. Paraná e Santa Catarina. subarenarium

5. Clípeo com faixa amarela subapical completa ou levemente interrompida no meio . catarinense

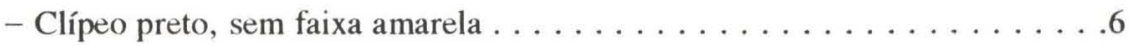

6. Sexto tergo preto ou com duas nódoas laterais amarelas . . . . . . 7

- Sexto tergo amarelo, com castanho somente na margem . . . . . . . 8

7. Mesoscuto com micro-reticulação densa e regular, tanto nos pontos grandes como nos intervalos carenados, quase fosco. Lobos pronotais com pequena área amarela. Escutelo e axilas com orla amarela larga . . . . paranaense

- Mesoscuto com pontuação densa e grossa, porém brilhante ou com micro-reticulação em pequena área. Lobos pronotais pretos. Escutelo e axilas com orla amarela estreita, interrompida no escutelo . . subarenarium

8. Quarto e quinto tergos com faixa discal amarela, terceiro com nódoas laterais amarelas, no primeiro e segundo com nódoas laterais castanhas obsoletas. 
Estria amarela das paroculares muito estreita na parte inferior e não chegando à sutura epistomal . . . . . . . . . . . . capixaba

- Terceiro ao quinto tergos com faixa discal amarela, no primeiro e segundo com nódoas laterais amarelas, prolongadas para o meio no primeiro. Estria amarela das paroculares larga, até a sutura epistomal inferiormente . . . .

bahianum

\section{Moureanthidium bahianum, sp.n.}

Diagnose. Fêmea com o tegumento amarelo no quinto e sexto tergos, os dois medianos com larga faixa discal amarela.

Holótipo fềmea. Tegumento preto com os seguintes desenhos amarelos: nódoa longa nas paroculares, pouco mais larga inferiormente e terminando a meia distância entre os alvéolos e ocelo mediano; duas nódoas interalveolares alongadas, pouco mais curtas que as carenas interalveolares; faixa estreita na metade posterior do vértice extendendo-se por curta distância atrás dos olhos; castanho-amarelado no lado ventral das antenas, do segundo ao quarto flagelômero. Estrias laterais amarelas no mesoscuto prolongadas anteriormente em faixa basal interrompida largamente no meio; metade apical das axilas e larga orla amarela no escutelo. Pernas castanhas, o tegumento mais escuro nos artículos basais; tégulas enegrecidas. Dois tergos basais com nódoas laterais amarelas, maiores no primeiro; terceiro e quarto tergos com larga faixa discal amarela e orla castanha, mais amarelada no quarto; quinto amarelo com orla translúcida amarelada e sexto amarelo com margem castanha.

Comprimento aproximado $6,33 \mathrm{~mm}$; comprimento da asa anterior $5,17 \mathrm{~mm}$; largura da cabeça $2,32 \mathrm{~mm}$; comprimento do olho $1,58 \mathrm{~mm}$; distância interorbital superior $1,42 \mathrm{~mm}$ e a inferior $1,02 \mathrm{~mm}$.

Holótipo fêmea. Brasil, Bahia: Vitória da Conquista, 10-20-V-1961, F.M. Oliveira leg., Depositado na Coleção de Entomologia Pe. J.S. Moure, Departamento de Zoologia da Universidade Federal do Paraná (DZUP).

Distribuição geogrática. Brasıl, Bahia.

\section{Moureanthidium capixaba, sp.n.}

Fig. 3

Diagnose. Macho com o sétimo tergo projetado em dois lobos angulosos, não digitiformes; com os dois tergos basais pretos, o terceiro só com nódoas laterais amarelas, quinto e sexto amarelos somente a orla amarela-acastanhada, quarto com faixa discal larga amarela. Fêmea com os três tergos basais como no macho, quinto e sexto amarelos com orla acastanhada, quarto com larga faixa amarela.

Holótipo macho. Tegumento preto com as seguintes áreas amarelas: quase todo o lado externo das mandíbulas, clípeo, nódoa larga nas paroculares inferiores porém estreitando para o meio e terminando bem abaixo da tangente inferior do ocelo médio; duas nódoas alongadas incluindo as carenas interalveolares; faixa 
estreita na metade posterior do vértice prolongada atrás dos olhos nos cantos superiores e área ventral do escapo; de um amarelo acastanhado no lado ventral do segundo ao sétimo flagelômero, pedicelo e primeiro flagelômero castanhos como também na face dorsal dos demais flagelômeros. Estria amarela lateral na metade basal do mesoscuto prolongada em faixa anteriormente, largamente interrompida no meio; nódoa amarela subapical nas axilas e estreita orla na parte sub-mediana do escutelo. Pernas castanhas com nódoas amarelas alongadas nos fêmures e tíbias anteriores e fêmures medianos, basitarsos anteriores e posteriores; nódoa pouco alongada nas tíbias medianas e posteriores e, mancha amarela discal nas coxas posteriores; tégulas de um castanho enegrecido. Dois tergos basais pretos, terceiro tergo com nódoas amarelas em forma de pequenas faixas laterais, quarto largamente amarelo no disco, quinto e sexto amarelos; do terceiro ao sex to com orla translúcida amarelo-acastanhada mais larga no meio; sétimo amarelo nos lobos e com ápice castanho; esternos com áreas castanhas e enegrecidas.

Comprimento aproximado $7,08 \mathrm{~mm}$; comprimento da asa anterior $6,42 \mathrm{~mm}$; largura da cabeça $2,40 \mathrm{~mm}$; comprimento do olho $1,66 \mathrm{~mm}$; distância interorbital superior $1,46 \mathrm{~mm}$ e a inferior $1,10 \mathrm{~mm}$.

Alótipo fêmea. Tegumento preto com estrias paroculares amarelas muito estreitas inferiormente e alargando muito pouco na altura dos alvéolos antenais, faixa amarela muito estreita na metade posterior do vértice. Mesoscuto e escutelo como no macho. Pernas castanhas. Dois tergos basais castanhos enegrecidos com nódoas obsoletas laterais castanhas, terceiro tergo com nódoas laterais amareladas, quarto ao sexto tergos como no macho, porém com uma tonalidade levemente acastanhada e orla castanha.

Comprimento aproximado $6,50 \mathrm{~mm}$; comprimento da asa anterior $5,42 \mathrm{~mm}$; largura da cabeça $2,32 \mathrm{~mm}$; comprimento do olho $1,60 \mathrm{~mm}$; distância interorbital superior $1,40 \mathrm{~mm}$ e a inferior $1,10 \mathrm{~mm}$.

Holótipo macho e alótipo fềmea. BRASIL, Espirito Santo: Santa Teresa, VI-1964, C. Tadeu Elias leg. . Parátipos da mesma localidade: 15-IV-64, C. Elias leg., um macho; 1-3-II-1968, C. e C.T. Elias leg., um macho; Rio de Janeiro: (Est. Silvestre), 8-III-1953, C.A.C. Seabra leg., um macho. Depositados na Coleção de Entomologia Pe. J.S. Moure (DZUP).

Distribuição geográfica. BRASIL, Espírito Santo e Rio de Janeiro.

\section{Moureanthidium catarinense, sp.n.}

Fig. 5

Diagnose. Macho com o sétimo tergo com dois lobos angulosos apicais, sem projeções digitiformes laterais; tergo basal com faixa amarela interrompida, segundo tergo com nódoas amarelas laterais, do terceiro ao sexto com larga faixa amarela discal e o bordo castanho. Fêmea com área amarela no clípeo; dois tergos basais como no macho, do terceiro ao quinto com faixa amarela estreita.

Holótipo macho. Tegumento preto com as seguintes áreas amarelas: quase todo o lado externo das mandíhulas, clípeo e paroculares, nestas o amarelo junto aos olhos e terminando a meia distância dos alvéolos ao ocelo mediano; nódoas 
interalveolares alongadas incluindo as carenas, porém unidas estreitamente tomando a forma de um $\mathrm{H}$; metade posterior do vértice com faixa prolongada atrás dos olhos onde alarga muito para novamente estreitar terminando pouco além da metade dos olhos; nódoa amarela genal alongada próxima às mandíbulas; antenas com o escapo amarelo ventralmente, restante do escapo e lado ventral do pedicelo ao nono flagelômero amarelo-acastanhado. Lobos pronotais com nódoa amarela; mesoscuto com estrias laterais amarelas prolongadas anteriormente em faixas laterais; larga margem amarela nas axilas, e um pouco mais estreita no escutelo; pernas enegrecidas nos artículos basais, com áreas castanhas e amarelo-acastanhadas; fêmures e tíbias anteriores e medianos e, lado posterior das tíbias posteriores com nódoa alongada amarela; coxas posteriores com nódoa amarela; basitarsos anteriores e posteriores amarelos no lado externo; tégulas amarelo-acastanhadas. Tergos enegrecidos, o primeiro com faixa amarela estreita interrompida no meio e alargando nos cantos, segundo tergo com nódoas laterais amarelas, terceiro e quarto com faixa discal amarela mais estreita no meio do terceiro; quinto ao sétimo largamente amarelos, com orla translúcida castanha e área castanha no disco do sétimo; esternos com áreas castanhas e castanho-amareladas.

Comprimento aproximado 7,08mm; comprimento da asa anterior $6,50 \mathrm{~mm}$; largura da cabeça 2,40mm; comprimento do olho $1,62 \mathrm{~mm}$; distância interorbital superior $1,50 \mathrm{~mm}$ e a inferior $1,12 \mathrm{~mm}$.

Alótipo fêmea. Tegumento preto com as seguintes áreas amarelas: faixa subapical no clípeo interrompida no meio, nódoa alongada nas paroculares, mais larga junto ao clípeo e estreitando em direção ao vértice; duas nódoas alongadas incluindo as carenas interalveolares; faixa amarela da metade posterior do vértice se extendendo até pequena área atrás dos olhos; antenas amarelo-acastanhadas. Mesoscuto com estrias laterais amarelas prolongadas anteriormente em faixas amplamente separadas no meio; axilas e escutelo com estreita orla amarela. Pernas posteriores castanhas, as anteriores e medianas com áreas ferrugíneas; tégulas ferrugíneas. Tergo basal com faixa amarela discal estreita interrompida no meio e mais larga nos flancos; segundo com nódoas laterais amarelas; do terceiro ao quinto com faixa amarela discal e larga margem castanha enegrecida.

Comprimento aproximado $6,25 \mathrm{~mm}$; comprimento da asa anterior $5,67 \mathrm{~mm}$; largura da cabeça 2,28mm; comprimento do olho $1,52 \mathrm{~mm}$; distância interorbital superior $1,42 \mathrm{~mm}$ e a inferior $1,10 \mathrm{~mm}$.

Variações nas fêmeas. A área amarela do clípeo formando faixa subapical completa em um dos parátipos e, em outro, reduzida a nódoas laterais amarelas; as faixas do terceiro e quarto tergos levemente interrompidas no meio e, duas nódoas obsoletas amareladas no sexto tergo de um dos parátipos.

Holótipo macho. Brasil, Santa Catarina: Seara (Nova Teutonia), XI-1951, L.E. Plaumann leg.. Alótipo fêmea de II-1957 e dois parátipos fêmeas de X-1956, da mesma localidade, coletados por F. Plaumann. Depositados na Coleção de Entomologia Pe. J.S. Moure (DZUP).

Distribuição geográfica. BRASIL, Santa Catarina. 


\section{Moureanthidium paranaense, sp.n.}

Figs 1 e 4

Diagnose. Macho com duas projeções digitiformes laterais no ápice do tergo distal como em $M$. subarenarium, difere pelo quinto esterno com duas áreas discais infladas, fracamente separadas na linha média. Colorido do tegumento como na espécie citada acima. Fêmea distinta de $M$. subarenarium pela pontuação do mesoscuto, com micro-reticulação densa até nas carenas entre os pontos.

Holótipo macho. Tegumento preto com as seguintes áreas amarelas: pequena nódoa discal nas mandíbulas, quase todo o clípeo exceto o ápice e a base, esta com área preta de contorno irregular; grande parte das paroculares inferiores estreitando em direção ao vértice e terminando abaixo da tangente do ocelo mediano; duas áreas alongadas incluindo as carenas interalveolares; faixa estreita na metade posterior do vértice um pouco prolongada atrás dos olhos; escapo amarelo na face ventral, restante do escapo e flagelômeros basais castanhos amarelados. Mesoscuto com estrias laterais amarelas prolongadas anteriormente em faixas laterais; base das axilas largamente amarela, a nódoa estreitando em direção ao escutelo, este com orla amarela estreita. Pernas enegrecidas nos artículos basais e com grande parte do tegumento amarelo-acastanhado; tarsômeros posteriores castanhos escuros; tégulas ferrugíneas. Tergos pretos, o primeiro com faixa discal amarela, segundo com nódoas amarelas nos flancos, do terceiro ao sexto com faixa discal amarela, mais estreita no terceiro e mais afastada do bordo no meio; margem do terceiro ao sexto translúcida amarela levemente acastanhada; sétimo amarelo levemente acastanhado e com ápice enegrecido; esternos com área basal quase preta, castanhos para o disco e amarelo-acastanhados distalmente.

Comprimento aproximado $6,50 \mathrm{~mm}$; comprimento da asa anterior $5,83 \mathrm{~mm}$; largura da cabeça $2,36 \mathrm{~mm}$; comprimento do olho $1,50 \mathrm{~mm}$; distância interorbital superior $1,42 \mathrm{~mm}$ e a inferior $1,04 \mathrm{~mm}$.

Alótipo fêmea. O tegumento lembra o do macho quanto às manchas amarelas porém com o clípeo e mandibulas pretos e nos tergos as faixas amarelas completas no primeiro e do terceiro ao quinto. Pernas mais escuras do que no macho, de um castanho escuro com nódoas castanhas e artículos basais pretos. Lobos pronotais com área discal amarela.

Comprimento aproximado $6,50 \mathrm{~mm}$; asa anterior com a extremidade gasta; largura da cabeça $2,32 \mathrm{~mm}$; comprimento do olho $1,52 \mathrm{~mm}$; distância interorbital superior $1,48 \mathrm{~mm}$ e a inferior $1,16 \mathrm{~mm}$.

Variações. Um parátipo macho com as mandibulas quase inteiramente amarelas no lado externo.

Holótipo macho e alótipo fêmea. Brasil, Paraná: Ponta Grossa (Vila Velha), o holótipo de 28-X-1967, Moure \& Willink leg.. Alótipo de 2-IV-1967, P. D. Hurd leg.. Parátipos das seguintes localidades: BrasiL, Paraná: Curitiba, J.S. Moure leg., XI-1941 um macho; X-1948 um macho; Laroca \& Graf leg., 17-XII-1965 um macho; Mitchell e Graf leg., 21-XI-1965 um macho; Piraquara, J.S. Moure leg., IX-X-1950 um macho; Foz do Iguaçu, Moure \& Mielke leg., 
18-II-1969 uma fềmea; Santa Catarina: Seara (Nova Teutonia), L.E. Plaumann leg., XI-1951 um macho; III-1951 uma fềmea; XI-1951 uma fềmea. Depositados na Coleção de Entomologia Pe. J.S. Moure (DZUP).

Distribuição geogrática. Brasil, Paraná e Santa Catarina.

AGRADECIMENTOS. A autora agradece ao Prof. Dr. Pe. J.S. Moure pelo acesso às notas sobre os tipos è à bibliografia.

\section{REFERÊNCIA BIBLIOGRÁFICA}

Schwarz, H.F. 1933. Some Neotropical Anthidiinae: Anthidium, Heteranthidium, and Dianthidium. Amer. Mus. Novitates 624: 1-27.

Recebido ent 15.IX.1994; aceito em 08.II.1995 